\title{
Ultrathin $\mathrm{MgB}_{2}$ films fabricated on $\mathrm{Al}_{2} \mathrm{O}_{3}$ substrate by hybrid physical-chemical vapor deposition with high $T_{\mathrm{c}}$ and $J_{\mathrm{c}}$
}

\author{
Yuhao Zhang ${ }^{1}$, Zhiyuan Lin ${ }^{1}$, Qian Dai, Dongyao Li, Yinbo Wang, \\ Yan Zhang, Yue Wang* and Qingrong Feng ${ }^{\dagger}$
}

State Key Laboratory for Mesoscopic Physics, Applied Superconductivity Center, and School of Physics, Peking University, Beijing 100871, People's Republic of China

\footnotetext{
${ }^{1}$ These authors contributed equally to this work.

*yue.wang@pku.edu.cn

†qrfeng@pku.edu.cn
}

\begin{abstract}
Ultrathin $\mathrm{MgB}_{2}$ superconducting films with a thickness down to $7.5 \mathrm{~nm}$ are epitaxially grown on (0001) $\mathrm{Al}_{2} \mathrm{O}_{3}$ substrate by hybrid physical-chemical vapor deposition method. The films are phase-pure, oxidation-free and continuous. The $7.5 \mathrm{~nm}$ thin film shows a $T_{\mathrm{c}}(0)$ of $34 \mathrm{~K}$, which is so far the highest $T_{\mathrm{c}}(0)$ reported in $\mathrm{MgB}_{2}$ with the same thickness. The critical current density of ultrathin $\mathrm{MgB}_{2}$ films below $10 \mathrm{~nm}$ is demonstrated for the first time as $J_{\mathrm{c}} \sim 10^{6} \mathrm{~A} \cdot \mathrm{cm}^{-2}$ for the above $7.5 \mathrm{~nm}$ sample at $16 \mathrm{~K}$. Our results reveal the excellent superconducting properties of ultrathin $\mathrm{MgB}_{2}$ films with thicknesses between 7.5 and $40 \mathrm{~nm}$ on $\mathrm{Al}_{2} \mathrm{O}_{3}$ substrate.
\end{abstract}




\section{Introduction}

Over the last few years, the potential use of superconductors in electronic devices has attracted increasing attention as the superconducting devices show extremely low noise performance [1]. Among these devices, hot electron bolometers (HEBs) [2] and superconducting single-photon detectors (SSPDs) [3] are expected to be two promising applications with high performance. SSPDs based on $\mathrm{NbN}$ have been demonstrated experimentally with the detection efficiency as high as $~ 57 \%$ [4]. However, their working temperature and response time are limited by the critical temperature $\left(T_{\mathrm{c}}\right.$ $\sim 16 \mathrm{~K}$ ) and electron-phonon coupling time $\left(\tau_{0} \sim 0.06 \mathrm{~ns}\right)$ of the $\mathrm{NbN}$. As a novel superconductor with $T_{\mathrm{C}} \sim 40 \mathrm{~K}$ and $\tau_{0} \sim 0.002 \mathrm{~ns}$ [5], $\mathrm{MgB}_{2}$ has considerable potential for use in these devices since it allows higher operation temperature and faster response time than $\mathrm{NbN}$ [6].

To fabricate HEBs and SSPDs, ultrathin superconducting $\mathrm{MgB}_{2}$ films must be fabricated to guarantee the films are not affected by the thermal energy of the stimulated electron [7]. Thus, the growth of ultrathin $\mathrm{MgB}_{2}$ films with a high transition temperature, high current-carrying capability and continuous surface is highly desirable. Due to difficulties in the synthesis, there are only a few reports on ultrathin $\mathrm{MgB}_{2}$ films so far $[8,9,10,11]$. Among these reports, it is worth noting that there is a large variance in the $T_{\mathrm{c}}$ of the films grown on different substrates and by different experimental techniques. In the work of Shimakage et al [8] and Shibata et al [9], ultrathin $\mathrm{MgB}_{2}$ films on $\mathrm{Al}_{2} \mathrm{O}_{3}$ substrate were fabricated by co-evaporation and molecular beam epitaxy respectively, showing that for $10 \mathrm{~nm}$ thick films the $T_{\mathrm{c}}$ is only about $20 \mathrm{~K}$, i.e., nearly half that of the $T_{\mathrm{c}}$ of bulk $\mathrm{MgB}_{2}$. Whereas, in the work of Wang et al [10] and Zhuang et al [11], where the hybrid physical-chemical vapor deposition (HPCVD) of ultrathin $\mathrm{MgB}_{2}$ films on SiC substrate was performed, it was shown that the $T_{\mathrm{c}}$ of the films with the same thickness of $10 \mathrm{~nm}$ can retain a high value of about $35 \mathrm{~K}$. Whether the significantly lower $T_{\mathrm{C}}$ of the films reported in [8] and [9] is due to the $\mathrm{Al}_{2} \mathrm{O}_{3}$ substrate or the growth techniques still needs to be clarified. This issue is important since, as a key parameter, the $T_{\mathrm{c}}$ value of the ultrathin $\mathrm{MgB}_{2}$ film will determine the prospects for the application of $\mathrm{MgB}_{2}$ in $\mathrm{HEBs}$ or SSPDs and therefore we need to figure out which are decisive factors in determining the $T_{\mathrm{c}}$ of ultrathin $\mathrm{MgB}_{2}$ films. Moreover, it is known that the $\mathrm{Al}_{2} \mathrm{O}_{3}$ substrate is one of the most common and widely used substrates in the epitaxial growth of $\mathrm{MgB}_{2}$ films and the manufacture of related superconducting devices. Hence, if it was experimentally found that one could also obtain a high $T_{\mathrm{c}}$ for ultrathin $\mathrm{MgB}_{2}$ films on $\mathrm{Al}_{2} \mathrm{O}_{3}$ substrate, the promise for $\mathrm{MgB}_{2}$ in applications such as SSPDs could have a more solid basis and attract more interest.

To address the above issue, we have conducted the HPCVD synthesis of ultrathin $\mathrm{MgB}_{2}$ films on $\mathrm{Al}_{2} \mathrm{O}_{3}$ substrate, which allows one to make a direct comparison with the report in [8] or [9]. In this paper, we present the main results. Encouragingly, the ultrathin $\mathrm{MgB}_{2}$ films grown on (0001) $\mathrm{Al}_{2} \mathrm{O}_{3}$ substrate with thicknesses down to $7.5 \mathrm{~nm}$ are all found to have $T_{\mathrm{c}}$ above $34 \mathrm{~K}$. A high critical current density is also achieved in a series of ultrathin films from $7.5 \mathrm{~nm}$ thick to $40 \mathrm{~nm}$ thick and in particular the critical current density of $7.5 \mathrm{~nm}$ thick $\mathrm{MgB}_{2}$ film is $\sim 10^{6} \mathrm{~A} \cdot \mathrm{cm}^{-2}$ at $16 \mathrm{~K}$. With a much higher $T_{\mathrm{c}}$ compared to films fabricated by other $\mathrm{MgB}_{2}$ deposition methods such as co-evaporation, our results may restore the promise of fabricating SSPDs with ultrathin $\mathrm{MgB}_{2}$ films on $\mathrm{Al}_{2} \mathrm{O}_{3}$ substrate.

\section{Experiment}

The HPCVD technique used in this experiment has been described in detail elsewhere [12]. Mg 
slugs (99.5\% in purity, $2 \mathrm{~g}$ in weight) are placed surrounding the (0001) $\mathrm{Al}_{2} \mathrm{O}_{3}$ substrates with square size of $5 \mathrm{~mm} \times 5 \mathrm{~mm}$ on a molybdenum susceptor. The high Mg vapor pressure, a prerequisite for the thermodynamic stability of the $\mathrm{MgB}_{2}$ phase, is realized by heating the $\mathrm{Mg}$ source to deposition temperatures in the range $\left(660-720{ }^{\circ} \mathrm{C}\right)$. Boron is supplied by the thermal decomposition of $\mathrm{B}_{2} \mathrm{H}_{6}$ gas (5\% in hydrogen, flow rate 1-4 sccm). Pre-purified hydrogen at $300 \mathrm{sccm}$ is continuously introduced, maintaining the total system pressure at $5.2 \mathrm{kPa}$ during the whole process. The thickness of the $\mathrm{MgB}_{2}$ films is controlled by precisely adjusting both the $\mathrm{B}_{2} \mathrm{H}_{6}$ flow rate and the deposition time, and is measured by either an atomic force microscope (AFM, SPI 3800N) or a scanning electron microscope (SEM, FEI DB 235) on half-etched samples. The film topography is investigated by the above SEM. Its phase purity and crystalinity are examined by $\mathrm{X}$-ray diffraction (XRD, Rigaku). The temperature dependence of resistivity is determined using a Quantum Design physical property measurement system (PPMS) with a standard four probe method employing silver paste as the contacts. The measurements of critical current density are conducted in PPMS on $5 \mu \mathrm{m} \times 80 \mu \mathrm{m}$ strips which are fabricated by standard photolithography and argon milling.

\section{Results and Discussion}

To accurately control the thickness of the ultrathin $\mathrm{MgB}_{2}$ films, the deposition time and the $\mathrm{B}_{2} \mathrm{H}_{6}$ flow rate are optimized according to the SEM and AFM measurement. By keeping the other parameters constant, the $\mathrm{H}_{2}$ flow rate $\sim 300 \mathrm{sccm}$, total pressure $\sim 5.2 \mathrm{kPa}$ and the deposition temperature $\sim 700{ }^{\circ} \mathrm{C}$, a series of films with thicknesses from 7.5 to $40 \mathrm{~nm}$ were synthesized. The estimated thickness based on the growth conditions is consistent with the measured thickness by AFM and SEM, as presented in table 1. As can be seen, for the series of $\mathrm{MgB}_{2}$ ultrathin films, the percentage deviation of the estimated thickness from the measured value is within $5 \%$. This indicates that the deposition thickness at the above conditions basically satisfies $10\left(\mathrm{~nm} \cdot \mathrm{min}^{-1} \cdot \mathrm{sccm}^{-1}\right) \times$ deposition time $(\mathrm{min}) \times \mathrm{B}_{2} \mathrm{H}_{6}$ flow rate $(\mathrm{sccm})$.

Table 1. The reaction conditions, estimated film thickness, measured thickness of $\mathrm{MgB}_{2}$ films and percentage deviation of the estimated thickness from the measured thickness.

\begin{tabular}{llll}
\hline $\begin{array}{l}\mathrm{B}_{2} \mathrm{H}_{6} \text { flow rate }(\mathrm{sccm}), \\
\text { deposition time }(\mathrm{min})\end{array}$ & Estimated value $(\mathrm{nm})$ & Measured value $(\mathrm{nm})$ & $\begin{array}{l}\text { Percentage } \\
\text { deviation }(\%)\end{array}$ \\
\hline $1,0.50$ & 5 & -- & -- \\
$1,0.75$ & 7.5 & 7.3 & 2.7 \\
$1,1.00$ & 10 & 9.7 & 3.0 \\
$2,1.00$ & 20 & 21.0 & 5.0 \\
$4,1.00$ & 40 & 41.5 & 3.8 \\
\hline
\end{tabular}

The x-ray diffraction results of the series of ultrathin $\mathrm{MgB}_{2}$ films are shown in figure 1 . For these films, the main diffraction peaks in the scans are from the substrate and $\operatorname{MgB}_{2}((0001)$ and (0002)), indicating that there is no obvious impurity phase and the samples are predominantly $\mathrm{MgB}_{2}$ with the $\mathrm{c}$ axis perpendicular to the substrates. These $\mathrm{XRD}$ results of the ultrathin films are consistent with the epitaxial growth of thick films on $\mathrm{Al}_{2} \mathrm{O}_{3}$ substrate reported in [13]. The basal plane of $\mathrm{MgB}_{2}$ and $\mathrm{Al}_{2} \mathrm{O}_{3}$ possess the same hexagonal atomic configuration and six-fold symmetry. Although an a-to-a alignment between $\mathrm{MgB}_{2}$ and $\mathrm{Al}_{2} \mathrm{O}_{3}$ results in $\sim 23 \%$ lattice mismatch, which would be unfavorable for epitaxial growth, a $30^{\circ}$ angle off a-to-a alignment provides a smaller $(\sim 11 \%)$ lattice 
mismatch that still allows an epitaxial growth [14]. Therefore, the growth relations of the epitaxial films are $[10 \overline{10}](0001) \mathrm{MgB}_{2} \|[11 \overline{20} 0](0001) \mathrm{Al}_{2} \mathrm{O}_{3}$ [14] for $\mathrm{MgB}_{2}$ films on $\mathrm{Al}_{2} \mathrm{O}_{3}$ substrate. The greater lattice mismatch between $\mathrm{MgB}_{2}$ and $\mathrm{Al}_{2} \mathrm{O}_{3}$, compared to that between $\mathrm{MgB}_{2}$ and $\mathrm{SiC}(\sim$ $0.42 \%$ ), may still result in more difficulties in fabricating $\mathrm{MgB}_{2}$ ultrathin films on $\mathrm{Al}_{2} \mathrm{O}_{3}$ substrate.

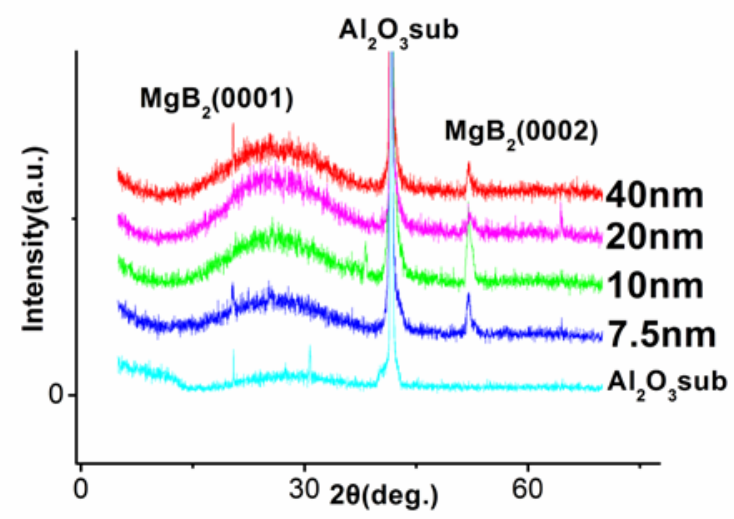

Figure 1. XRD scans of the $\mathrm{Al}_{2} \mathrm{O}_{3}$ substrate and $\mathrm{MgB}_{2}$ films with different thickness.

The SEM images of films with thicknesses of 5, 7.5, 10 and $20 \mathrm{~nm}$ are shown in figure 2. The morphology of this series of films indicates the existence of island growth in the HPCVD fabrication of $\mathrm{MgB}_{2}$ ultrathin films on $\mathrm{Al}_{2} \mathrm{O}_{3}$ substrate. The initial nucleation of discrete islands, as shown in the $5 \mathrm{~nm}$ thin film, coalesce to connected grains when the thickness increases to $7.5 \mathrm{~nm}$, where the whole thin film shows zero-resistivity superconducting characteristics. For the 10 and $20 \mathrm{~nm}$ film, most of the grains are connected to form a continuous film, where $T_{\mathrm{c}}$ is relatively unchanged. The film surface is found to be completely smooth when the film grows to $40 \mathrm{~nm}$ in thickness. This is consistent with our previous work reported in [13].

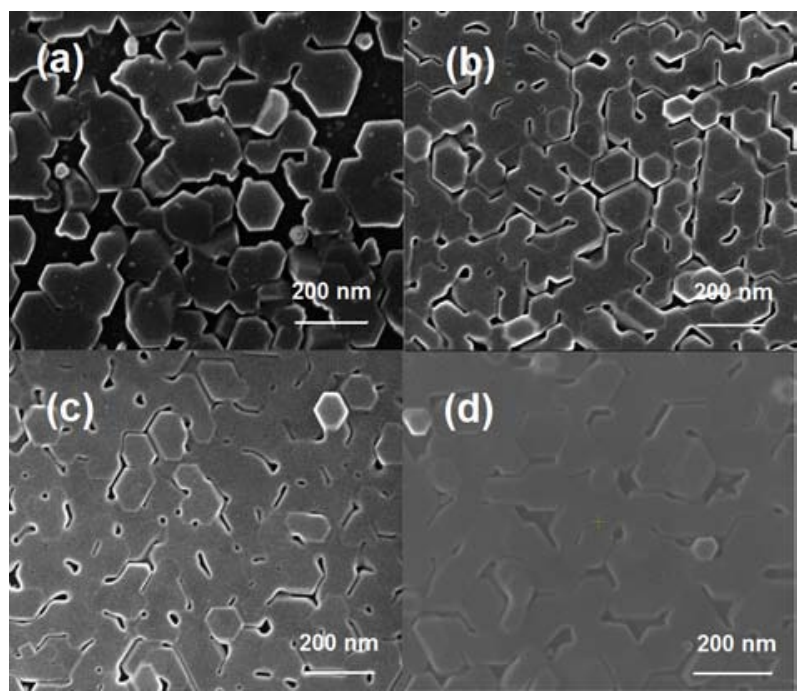

Figure 2. SEM images of the $\mathrm{MgB}_{2}$ thin films with different thicknesses on $\mathrm{Al}_{2} \mathrm{O}_{3}$ substrates: (a) $5 \mathrm{~nm}$, (b) $7.5 \mathrm{~nm}$, (c) $10 \mathrm{~nm}$ and (d) $20 \mathrm{~nm}$. 


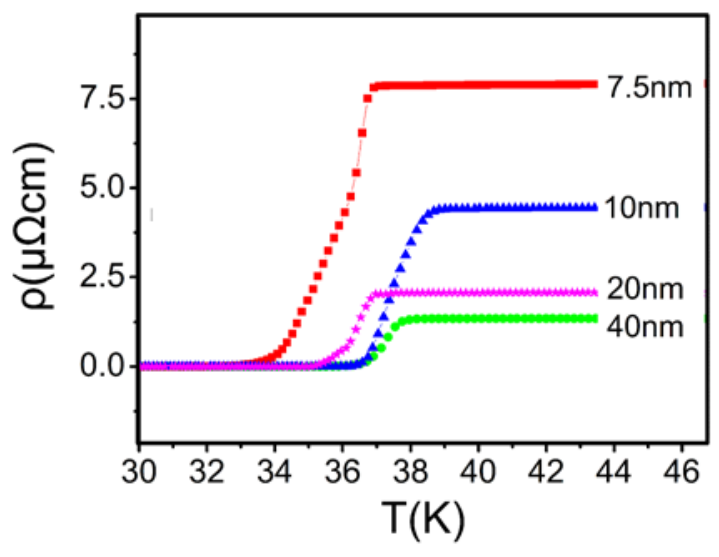

Figure 3. Resistivity versus temperature curves for $\mathrm{MgB}_{2}$ films with thicknesses of 7.5, 10, 20 and $40 \mathrm{~nm}$ on $\mathrm{Al}_{2} \mathrm{O}_{3}$ substrates.

In figure 3, the resistivity versus temperature curves are presented for the series of films. For the $5 \mathrm{~nm}$ thin film, no superconducting transition is detected, since no connection is formed between $\mathrm{MgB}_{2}$ islands, as shown in figure 2(a). The $T_{\mathrm{c}}$ of $10 \mathrm{~nm}$ thin film and $20 \mathrm{~nm}$ thin film are similar due to their similar degree of the grain interconnection, as shown in figures 2(c) and (d). The $T_{\mathrm{c}}$ (onset), $T_{\mathrm{c}}(0)$ and $\rho(42 \mathrm{~K})$ of the films determined from figure 3 are presented in table 2 . As can be seen, the transition width, $\Delta T(\mathrm{~K})=T_{\mathrm{c}}$ (onset) $-T_{\mathrm{c}}(0)$, decreases with the increase of the film thickness, indicating a better electronic superconducting property due to better continuity in the film surface, as shown in figure 2. Unlike the reported $\mathrm{MgB}_{2}$ ultrathin films on SiC substrate, with a dramatic decrease in $T_{\mathrm{C}}(0)$ and a dramatic increase in $\rho(42 \mathrm{~K})$ as the thickness is reduced [10], the variation of the $T_{\mathrm{c}}(0)$ and $\rho(42 \mathrm{~K})$ of $\mathrm{MgB}_{2}$ ultrathin films on $\mathrm{Al}_{2} \mathrm{O}_{3}$ substrate is smaller, as $T_{\mathrm{c}}(0)$ goes from $34 \mathrm{~K}$ for $7.5 \mathrm{~nm}$ thin film to $37 \mathrm{~K}$ for $40 \mathrm{~nm}$ film and $\rho(42 \mathrm{~K})$ goes from $1.35 \mu \Omega \cdot \mathrm{cm}$ for $40 \mathrm{~nm}$ film to 7.90 $\mu \Omega \cdot \mathrm{cm}$ for $7.5 \mathrm{~nm}$ thin film. At present we do not fully understand this relatively mild variation of the $T_{\mathrm{c}}(0)$ and $\rho(42 \mathrm{~K})$, but have noted that it might relate to the existence of a very thin epitaxially grown $\mathrm{MgB}_{2}$ layer below the islands shown in figure 2. This issue is under further investigation in our group. On the other hand, this lower sensitivity of the superconductivity with the decrease of film thickness is apparently advantageous for the application of $\mathrm{MgB}_{2}$ ultrathin films.

Table $2 . T_{\mathrm{c}}$ (onset), $T_{\mathrm{c}}(0)$ and residual resistivity $\rho(42 \mathrm{~K})$ of $\mathrm{MgB}_{2}$ ultrathin films with different thickness derived from figure 3.

\begin{tabular}{lllll}
\hline $\begin{array}{l}\text { Thickness } \\
(\mathrm{nm})\end{array}$ & $\begin{array}{l}\text { Transition } \\
\text { temperature }\end{array}$ & $\begin{array}{l}\text { Onset } \\
\text { temperature }\end{array}$ & $\begin{array}{l}\Delta T(\mathrm{~K}) \\
T_{c}(\text { onset })-T_{c}(0)\end{array}$ & $\begin{array}{l}\text { Residual resistivity } \\
\rho(42 \mathrm{~K})(\mu \Omega \cdot \mathrm{cm})\end{array}$ \\
\hline 7.5 & $T_{c}(0)(\mathrm{K})$ & $T_{c}$ (onset) $(\mathrm{K})$ & & 7.90 \\
10 & 34.0 & 36.5 & 2.5 & 4.46 \\
20 & 36.4 & 38.5 & 2.1 & 2.08 \\
40 & 35.6 & 36.9 & 1.3 & 1.35 \\
\hline
\end{tabular}

The self-field critical current density $J_{\mathrm{c}}(T)$, determined by $1 \mu \mathrm{V}$ criteria from the $I-V$ curves at different temperatures [11], of the series of ultrathin $\mathrm{MgB}_{2}$ films are shown in figure 4. The $J_{\mathrm{c}}(16 \mathrm{~K})$ value of the $7.5 \mathrm{~nm}$ thin film is $\sim 10^{6} \mathrm{~A} \cdot \mathrm{cm}^{-2}$, which is the first so far reported critical current density 
of $\mathrm{MgB}_{2}$ ultrathin film down to $7.5 \mathrm{~nm}$. While the $J_{\mathrm{c}}(T)$ of the films on $\mathrm{Al}_{2} \mathrm{O}_{3}$ substrate are a little lower than that of $\mathrm{SiC}$ substrate $[10,11]$, the $J_{\mathrm{c}}(20 \mathrm{~K})$ of $10 \mathrm{~nm}$ film on $\mathrm{Al}_{2} \mathrm{O}_{3}$ substrate is nearly equal to that of $10 \mathrm{~nm}$ film on $\mathrm{SiC}$ substrate at $1 \times 10^{6} \mathrm{~A} \cdot \mathrm{cm}^{-2}$. This high critical current density demonstrates the excellent crystalinity of connectivity between grains of the ultrathin $\mathrm{MgB}_{2}$ films on $\mathrm{Al}_{2} \mathrm{O}_{3}$ substrate.

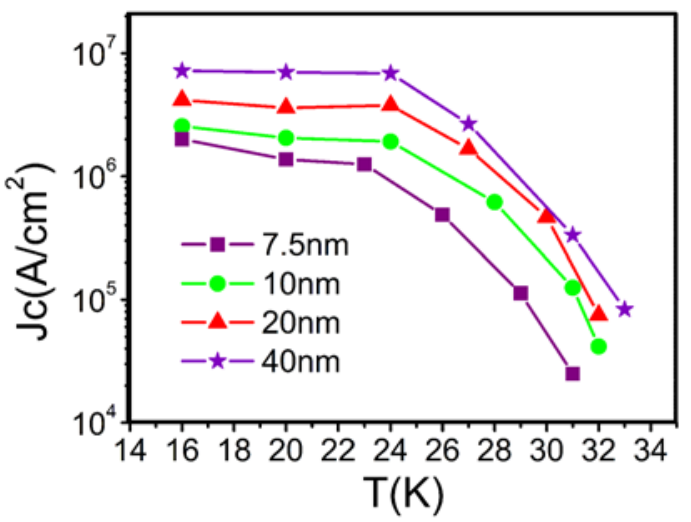

Figure 4. Temperature dependence of $J_{c}$ for $\mathrm{MgB}_{2}$ films with thicknesses of 7.5, 10, 20 and $40 \mathrm{~nm}$ on $\mathrm{Al}_{2} \mathrm{O}_{3}$ substrates.

Until recently, there have been only a few reports on ultrathin $\mathrm{MgB}_{2}$ films, including the films on $\mathrm{Al}_{2} \mathrm{O}_{3}$ substrate fabricated by co-evaporation by Shimakage et al [8] and molecular beam epitaxy by Shibata et al [9], and the films on SiC substrate fabricated by HPCVD by our group [10] and Zhuang et al [11]. Overcoming the difficulty of fabrication due to the relatively large mismatch between $\mathrm{Al}_{2} \mathrm{O}_{3}$ and $\mathrm{MgB}_{2}$, our $7.5 \mathrm{~nm}$ thin film on $\mathrm{Al}_{2} \mathrm{O}_{3}$ substrate synthesized by HPCVD has $T_{\mathrm{c}}$ not only much higher than the 20-22 $\mathrm{K} T_{\mathrm{c}}$ for $10 \mathrm{~nm}$ films by other $\mathrm{MgB}_{2}$ deposition methods [8, 9], but also higher than $T_{\mathrm{c}}$ of $7.5 \mathrm{~nm}$ film on $\mathrm{SiC}$ substrate $[10,11]$. Our results of continuously connected 7.5-10 $\mathrm{nm} \mathrm{MgB}_{2}$ films with high $T_{\mathrm{c}}$ and $J_{\mathrm{C}}$ values effectively dismiss the doubt that the large decrease in $T_{\mathrm{C}}$ with the decrease of film thickness may be intrinsic and unavoidable. Our results also indicate that amongst different growth techniques, HPCVD can produce rather clean and high quality ultrathin $\mathrm{MgB}_{2}$ films on different kinds of substrates. This would have a positive effect on the application of $\mathrm{MgB}_{2}$ in superconducting devices such as SSPDs.

\section{Conclusion}

In summary, ultrathin $\mathrm{MgB}_{2}$ films down to $7.5 \mathrm{~nm}$ have been epitaxially grown on $\mathrm{Al}_{2} \mathrm{O}_{3}$ substrate by the HPCVD method. The $7.5 \mathrm{~nm}$ thin film shows a $T_{\mathrm{c}}(0)$ of $34 \mathrm{~K}$, a resistivity of 7.90 $\mu \Omega \cdot \mathrm{cm}$ at $42 \mathrm{~K}$ and a critical current density of $\sim 10^{6} \mathrm{~A} \cdot \mathrm{cm}^{-2}$ at $16 \mathrm{~K}$. The $T_{\mathrm{c}}$ of the $7.5 \mathrm{~nm}$ sample is the highest so far in films with the same thickness grown on different substrates by different techniques. Our results demonstrate the excellent possibility of the application of ultrathin $\mathrm{MgB}_{2}$ films on $\mathrm{Al}_{2} \mathrm{O}_{3}$ substrate in superconducting devices including SSPDs.

\section{Acknowledgments}

This work is supported by NSFC (Nos. 50572001, 10804002, 90606023, 20731160012, and 10804003), MOST of China (973 Program, Nos. 2006CD601004, 2007CB936202/04, and 2009CB623703), NSFC/RGC (N 
HKUST615/06), and the National Foundation for Fostering Talents of Basic Science under grant No. J0630311.

\section{References}

[1] Rowell J M 2002 Nat. Mater. 15

[2] Hajenius M, Baselmans J J, Baryshev A, Gao J R, Klapwijk T M, Kooi J W, Jellena W and Yang Z Q 2006 J. Appl. Phy. 100074507

[3] Semenov A D, Gol’tsman G N and Sobolewski R 2002 Supercon. Sci. Technol. 15 R1

[4] Rosfjord K M, Yang J K W, Dauler E A, Kerman A J, Anant V, Voronov B M, Gol'tsman G N and Berggren K K 2006 Opt. Express 14527

[5] Parlato L, Latempa R, Peluso G, Pepe G P, Cristiano R, Sobolewski R 2005 Supercond. Sci. Technol. 181244

[6] Cherednichenko S, Drakinskiy V, Ueda K and Naito M 2007 Appl. Phys. Lett. 90023507

[7] Sobolewski R, Verevkin A, Gol’tsman G N, Lipatov A and Wilsher K 2003 IEEE Thans. Appl. Supercond. 13 1151

[8] Shimakage H, Tatsumi M and Wang Z 2008 Supercond. Sci. Technol. 21095009

[9] Shibata H, Maruyama T, Akazaki T, Takesue H, Honjo T and Tokura Y 2008 Physica C 4681992

[10] Wang Y Z, Zhuang C G, Sun X, Huang X, Fu Q, Liao Z M, Yu D P and Feng Q R 2009 Supercon. Sci. Technol. 22125015

[11] Zhuang C G, Chen K, Redwing J M, Li Q and Xi X X 2010 Supercon. Sci. Technol. 23055004

[12] Zhuang C G, Meng S, Zhang C Y, Feng Q R, Gan Z Z, Yang H, Jia Y, Wen H H and Xi X X 2008 J. Appl. Phys. 104013924

[13] Zhuang C G, Tan T, Wang Y Z, Bai S S, Ma X B, Yang H, Zhang G H, He Y S, Wen H H, Xi X X, Feng Q R and Gan Z Z 2009 Supercon. Sci. Technol. 22025002

[14] Tian W, Pan X Q, Bu S D, Kim D M, Choi J H, Patnaik S and Eom C B 2002 Appl. Phys. Lett. 81685 